\title{
2006-1857: ENGINEERING STUDENTS AND LAW CONFERENCES
}

\section{Douglas Sicker, University of Colorado-Boulder}

Dr. Douglas C. Sicker has held various positions in academia, industry and government. Presently, Doug is an assistant professor in the Department of Computer Science at the University of Colorado at Boulder with a joint appointment in the Interdisciplinary Telecommunications Program. Prior to this he was Director of Global Architecture at Level 3 Communications, Inc. Prior to this, Doug was Chief of the Network Technology Division at the Federal Communications Commission (FCC). Doug has also held faculty and industry positions in the field of medical sciences. Doug is a senior member of the IEEE, as well as a member of the ACM and the Internet Society. He serves on the faculty of the Institute for Regulatory Law and Economics. He was also the Chair of the Network Reliability and Interoperability Council steering committee, an FCC federal advisory committee that focuses on network reliability, wire line spectral integrity and Internet peering and interconnection. Doug also served on the Technical Advisory Council of the FCC. His research interests include network security, technology based policy and telecommunications policy. His teaching interests include distributed systems, network security and telecommunications public policy. Doug holds a PhD from the University of Pittsburgh.

\section{Tom Lookabaugh, University of Colorado-Boulder}




\section{Engineering Students and Law Conferences}

\section{Abstract}

The direct exposure of students to both the content and the culture of legal students, faculty, and professionals is highly appropriate in adding public policy sophistication. It also engenders substantial angst and grumbling, particularly among engineering students. To build an understanding of how students react to public policy conferences, we embarked on a combination of qualitative (interview based) and quantitative (survey based) research. We first surveyed seven students then administered an anonymous online survey with 67 responses. In this paper we describe the program and conferences, the results of both our interviews and surveys, and our recommendations for both these programs and similar efforts to introduce students to public policy debates through high quality legally oriented conferences.

\section{Introduction}

The Interdisciplinary Telecommunications Program at the University of Colorado educates master's students in a mixture of engineering, business, economics, and law; about half the program's students are engineers. For the last four years, as part of the curriculum, students have been required to attend a year's worth of conferences from the Silicon Flatirons

Telecommunications Program; these conferences have strong legal content and emphasis and are hosted by the university's law school. Recent examples include "The Digital Broadband Migration: Rewriting the Telecom Act," "Open Source, Open Standards, and the Future of the Internet," "The End of Politics as We Knew It: Examining the Internet and its Impact on Political Participation," and "Searching for the Third Broadband Pipe." A typical conference consists of 3 to 4 one hour panel sessions discussing different aspects of the conference's topics. Panels are usually comprised of a mix of lawyers, legal scholars, business executives, technologists, and government officials. The conferences are highly regarded by lawyers and legal academics alike.

The direct exposure of students to both the content and the culture of legal students, faculty, and professionals is highly appropriate in adding public policy sophistication. It also engenders substantial angst and grumbling, particularly among engineering students. To build an understanding of how students react to public policy conferences, we embarked on a combination of qualitative (interview based) and quantitative (survey based) research. We first surveyed seven students then administered an anonymous online survey with 67 responses. In this paper we describe the program and conferences, the results of both our interviews and surveys, and our recommendations for both these programs and similar efforts to introduce students to public policy debates through high quality legally oriented conferences.

\section{The Interdisciplinary Telecommunications Program and the Silicon Flatirons Telecommunications Program}

The Interdisciplinary Telecommunications Program (ITP) and the Silicon Flatirons Telecommunications Program (SFTP) are sister programs within the University of Colorado at 
Boulder. The ITP is a master's degree-granting program within the College of Engineering, and the SFTP is a policy-based conference series hosted by the School of Law. ITP and SFTP regularly co-host conferences with each other and coordinate on many other matters that lie at the intersection of technology and policy. Students from the ITP attend SFTP events as part of a graduate seminar course. This course focuses on exposing ITP students to policy and business issues in telecommunications and also serves as a compulsory writing seminar (directed at improving the writing skills of these students).

\subsection{The Interdisciplinary Telecommunications Program}

Founded in 1971, ITP is the oldest telecommunications degree program in the country; combining technology knowledge with the business, economic, and regulatory insights necessary to thrive in a world of increasingly ubiquitous networks. ${ }^{1}$ The mission of CU's ITP is the advancement of telecommunications science as its own discipline through research and education of technology, economics, management and policy issues. The historic boundaries that separated the various segments of the telecommunications industry (i.e., individual networks for voice, video, and data) are disappearing, and telecommunications networks continue to converge with information technology as the Internet increasingly shapes the industry. Reflecting these changes, ITP strives to educate students in all aspects of telecommunications, including wired and wireless telephone, the Internet, satellite communication, cable television, data networks and other forms of human interaction with technology.

Telecommunications is a field that is no longer a matter of technology alone - it has matured to implicate complicated business and management problems, as well as legal, political and regulatory issues - and it is essential that today's managers understand both the technology and complex multidisciplinary environments that characterize the modern network. Among the explicit goals of ITP are to: (1) Expose technology students to the policy and regulatory issues facing telecommunications. (2) Support and develop policy and technology conferences in conjunction with the law school's Silicon Flatirons Telecommunications Program; and (3) Develop discourse between telecommunication service providers, vendors, regulators, educators and users for ongoing learning opportunities through individual courses and certificates.

\subsection{Silicon Flatirons Telecommunications Program}

The Silicon Flatirons Telecommunications Program, co-sponsored by ITP and the Law School, offers an ongoing series of seminars, conferences and other activities designed to illuminate issues of regulation, policy, and law of telecommunications, particularly as they interact with economics, technology and business. ${ }^{2}$ Capitalizing on the strong presence of the local telecommunications industry, the University of Colorado created the Silicon Flatirons Telecommunications Program to bring to campus individuals from legal, technical, regulatory and business backgrounds to discuss issues facing the telecommunications and information technology industries. The program pursues three basic goals: (1) to elevate the debate around technology policy issues; (2) to facilitate networking and the development of "human capital" in the Colorado technology community; and (3) to inspire student interest in technology law.

Silicon Flatiron's central ambition is to develop programs on cutting edge topics that both inform our audience and expose them to new ideas. Each year, Silicon Flatirons hosts nine seminars and 
an annual symposium. It regularly draws over 200 people to each event, split evenly between students and professionals from the technology community. The academic environment and strong participation from local industry facilitate a healthy balance between examining theoretical perspectives and real world insights. Notably, the Program provides a forum for analyzing the continually changing dynamics in the telecommunications and information technology marketplace and regulatory environment. In so doing, it continues to prepare students to participate in our emerging information economy and society.

Examining what legal and regulatory reforms are necessary to meet the challenges created by technological change constitutes the core of Silicon Flatiron's mission. Notably, the Internet and the migration from analog technologies to a broadband digital environment continue to raise difficult technological, business and policy questions. Over the past several years, Silicon Flatirons has hosted a number of stellar speaker to address such issues, including Michael Powell, FCC Chairman; Kathleen Abernathy, FCC Commissioner; Craig Mundie, Microsoft Chief Technology Officer; Fritz Hollings, Senate Commerce Committee Chairman; Michael Gallagher, Assistant Secretary of Commerce for Communications and Information; Lawrence Lessig, Stanford Law Professor and Author; the CEOs of Level 3 Communications, Qwest Communications, Comcast, and Time Warner Telecom; and two heads of the Justice Department's Antitrust Division.

\section{Qualitative Research - Semi-Structured Interviews}

To understand ITP student responses and attitudes towards SFTP conferences, we used a combination of qualitative and quantitative research techniques in a practice often called triangulation. ${ }^{3,4}$ The first phase of our research used semi-structured interviews in a simplified version of Grounded Theory based qualitative research. ${ }^{5}$ Semi-structured interviews consist of a pre-determined set of questions that are asked of each interviewee, but allow the conversation to diverge from answering the questions depending on the responses of the interviewee and conversation between interviewee and interviewers. We used the set of questions given in Table 1 consistently with each of our seven ITP student interviewees selected from volunteers who had attended SFTP conferences in the previous semester. Both of the authors were present in all interviews and interviews were clearly not anonymous. The lack of anonymity could lead to some bias in responses (the interviewers are faculty and therefore involved in certain circumstances in evaluating the interviewees) but we hoped to remove this source of bias in the subsequent, anonymous survey stage.

1. How many SFTP conferences have you attended and when? How did you attend them (in person or through distance education)?

2. What is your background (education, professional)?

3. What did you expect to get out of the conference(s)? Were your expectations met?

4. Was the conference an efficient use of your time? Would there be any way to make it more efficient?

5. How relevant was the conference to your education at CU and to your anticipated career? How well did the conferences tie into your coursework?

6. Is the conference format effective? What might make it more effective? 
7. What new concepts or information of importance have you learned from conferences?

What has left you more confused?

8. How effective were any social networking opportunities for you?

9. Were the conferences enjoyable? Why or why not?

Table 1. Semi-structured Interview Questions.

We recorded each interview with permission of the interviewee, then subsequently transcribed them. We then applied the "coding" concept of Grounded Theory to identify key concepts in each element of interviewee response and to subsequently group and categorize concepts, looking for similarities and contrasts. The resulting categorization and supporting or elaborating paraphrased interview fragments are given in Appendix 1; the major points can be summarized as:

- A general appreciation of the conferences' exposure to business and government leaders, trends in the telecommunications industry, and as a vehicle for learning about policy and regulatory issues.

- Frustration around lack of context to understand the panel-style presentations and debates. This frustration was strongest for first semester international students but manifested itself in different ways for several interviewees. Some critiqued the format of the conferences. Interestingly, even the most frustrated students indicated a substantial increase in context after a single semester of study in the ITP program.

- An interest in using other elements of the ITP curriculum, particularly the required seminar course that is directly linked to SFTP attendance, to better prepare and review SFTP content. An intriguing interest in being directly involved in the discourse (by being asked questions during the conferences and by involvement in post conference discussions).

- Some concerns around technical quality of recordings by distance education students, but a general appreciation of the conferences and acceptance of the limitations imposed by distance education.

- An appreciation of the social networking opportunities but with some frustration around particular interaction dynamics.

We used the results of the semi-structured interviews to frame questions to ask in the form of a survey instrument with the goals of both improving the size of the population sample and using anonymity to reduce potential bias in responses.

\section{Quantitative Research - Survey}

The results of our interviews served to inform the structure and content of a survey we subsequently developed. The interviews highlighted a number of issues regarding the effectiveness and enjoyment of the SFTP events. They also served to pinpoint some concerns or 
dissatisfactions of the students. Overwhelmingly, the interviews suggested that the students found these events to be enjoyable (contrary to perceptions that we might attribute to the 'squeaky wheel' effect of some outspokenly critical students.) The students also found the events to provide an effective way of gaining exposure to public policy issues. However, the students did indicate some dissatisfaction with (1) the writing requirements, (2) the forced attendance, (3) the poor video and audio quality (for distance students) and (4) the limited opportunity to engage the speakers following the event. Based on the above findings, we implemented an online survey; the contents of which can be found in Appendix B along with summarized results.

\subsection{Demographics}

Using the Zoomerang survey tool ${ }^{6}, 67$ respondents were surveyed concerning their opinions of the SFTP events. These respondents were all present or former ITP students and composed a wide variety of technical and non-technical backgrounds. Nearly $80 \%$ of these individuals have technical backgrounds (meaning undergraduate degrees in engineering, science or mathematics) and $70 \%$ have two or more years professional work experience. ITP has a strong international student body and the survey reflects this with $36 \%$ of the respondents being from abroad. Finally, the majority of those surveyed attended the SFTP events in the last 18 months.

\subsection{Survey Results}

The main body of the survey contained a long series of questions employing a seven-point Likert scale to measure students' attitudes on a broad range of topics concerning the SFTP events. We now present some of the more interesting findings.

In assessing aspects of the events that the students liked, the survey indicated the following:

- Students overwhelming found the SFTP events to be enjoyable.

- Students very strongly believed that the SFTP events help explain current or predict the future state of the industry and that it provides an efficient way to learn policy.

- Students generally found the panels to be more effective when speakers take strong positions.

- Students found SFTP to be useful for generating topics for term papers for other classes.

We will return to these topics later in the recommendations section of the paper.

In assessing aspects of the events that the students disliked, the survey indicated the following:

- Student found that there was not sufficient preparation or review of SFTP conferences in the associated seminar class.

- More than half of the students felt that the discussions held during the events were difficult to understand. However, these same students stated that after one semester the material become much easier to understand. 
- More than half of the students felt that the material wasn't relevant to the rest of the ITP curriculum.

- Students believed that they should be more engaged with the program.

- Students strongly believe that SFTP did not provide sufficient coverage of international topics and that there was not enough technical coverage of materials.

Again, we will return to these topics later in the recommendations section of the paper.

In a separate set of questions, which also employed a seven-point Likert scale to measure students' attitudes, distance education student (i.e., students who obtain their content through DVDs, tapes or streaming video) were asked about their experience viewing SFTP events. These students had several concerns with the experience they received. Most strongly, the students found it difficult to understand the questions from the audience. They also found the recording quality to be poor; so much so that they were sometimes unable to identify which of the panelists were speaking.

\subsection{Cross Tabulation}

A number of cross tabulations provided interesting insights into the opinions of our students. First, students with technical degrees were somewhat less likely to find SFTP events as an efficient way to learn policy (an average of 3.13 for students with technical degrees vs. 2.57 for students without technical degrees on a 7-point Likert Scale testing from 1 = "Strongly Disagree" to 7 = "Strongly Agree" the statement "SFTP is an efficient way to learn policy.") Second, students with more than 5 years of work experience were more likely to enjoy the events and find them an efficient way to learn (an average of 2.88 for students with 5 or more years of work experience degrees vs. 3.15 for students with less than 5 years work experience on the statement "SFTP is an efficient way to learn policy," and an average of 2.82 for students with 5 or more years work experience vs. 3.35 for students with less than 5 years on the statement "SFTP is enjoyable."). We suspect that the maturity and exposure to industry issues associated with more work experience increases interest and enjoyment of the conference content; more explicit motivation is required for students with less work experience. Lastly, international students were less likely to enjoy SFTP events and felt like they had much less context (an average of 3.44 for international students vs. 2.88 for domestic students on the statement "SFTP is enjoyable" and an average of 3.45 for international students vs. 5.21 for domestic students on the statement "I lacked the context to understand SFTP conferences"); however, these same students were more likely to respond that by the second term they were able to better understand the material (an average of 2.54 for international students vs. 2.97 for domestic students on the statement "It is much easier to understand SFTP conferences after a semester in ITP."). This initial lack of understanding in the first term may contribute to them not enjoying the events.

\subsection{Additional Responses}

In the survey, we gave several opportunities for the students to expand upon their answers by providing additional written comments. In this section, we discuss these comments. 
The first of these additional responses solicited students for "any other comments (positive or negative) on SFTP". Generally, the written responses correlated closely with the results described previously, and sometimes amplified or simply elaborated on these positions. The most frequent comments were those strongly supporting the SFTP. These statements generally expressed that the events were enjoyable and thought provoking. However, three concerns were expressed repeatedly and included:

- A dislike of the written reports

- The lack of preparatory material or context for the conference topics

- The lack of interaction between the students and the speakers

We will return to these concerns in the recommendations section and propose some possible remedies.

The next set of written comments was in response to the students' opportunity for social networking with the speakers. It is customary for the speakers and the audience to gather for drinks and hors d'oeuvres following an SFTP event. These receptions are well attended and may include 200 individuals. Some of the respondents indicated that the opportunities for social networking were great. However, many of the students indicated that they felt either too intimidated or had no opportunity to approach the speakers. Several students indicated that the speakers were "swamped" with members of the audience and that it was therefore impossible to network. Some of the students recommended providing a smaller (more intimate) setting for students and speaker to interact. In examining this issue, it is not surprising to find that some of the students are outgoing and have no reservation in approaching the speakers. Likewise, it is not surprising to find that other students are too intimidated to engage the speakers. Nonetheless, we plan to examine ways of improving the interaction among the students and the speakers. We will return to this issue in the recommendation section later in the paper.

The next set of written comments was in response to the experiences of distance education students with SFTP (students watching recorded coverage of the events). There was a strong opinion that the video and sound was not done well. Among the concerns were: (1) issues with video quality, (2) issues with sound quality - particularly not being able to hear the answers from the audience, and (3) poor postproduction. Again, we will discuss these issues later in the recommendations section of the paper. 


\section{Recommendations and Conclusions}

Our interview based findings in Section 3 were for the most part (although not always) confirmed by our survey findings described in Section 4; we consider the survey findings to be more authoritative based on the larger sample size and the anonymous character of the survey. Taking these findings together, we have the following recommendations for the use of SFTP conferences in the ITP program and for other similar efforts to introduce legal and policy conferences into technical and interdisciplinary programs.

- Overall, students appreciate the value of the SFTP conferences and when combined with their pedagogical value this strongly supports their continuation.

- Context building should be provided for students prior to each conference and complemented by a participatory review and discussion after the conference. In particular students are surprisingly interested in being forced to ask questions during the question and answer session of each conference. Moderated questions that arise in a post conference discussion could be forwarded to speakers to lower student interaction barriers without overwhelming the speaker.

- Students should either be delayed in attending conferences until after a semester of relevant preparation (e.g., a course that provides legal and policy context) or the period of attending SFTP conferences should be extended over multiple semesters in order to amortize the steep but fairly rapid learning curve required to appreciate policy discussions.

- International coverage is valued by both international and domestic students.

- Distance education requires good production values with a focus on capturing all the content (e.g., audience questions). If distance education is intended, it should be done well.

- Speaker interaction is highly valued by students, but could be made less intimidating and more intimate, particularly for students who are less outgoing. One possibility is a short (say 15 minute) student and speaker only session between the end of the conference and a broad social event.

- There is a demand for more technical content but this could be addressed separately rather than in a way that dilutes the widely appreciated policy content of the conferences.

\section{Bibliography}

1. See http://itp.colorado.edu

2. See http://www.silicon-flatirons.org

3. Fielding, Nigel G. and Fielding, Jane L., Linking Data, Beverly, Hills, CA: Sage Publications, 1986.

4. Denzin, Norman K., The Research Act: A Theoretical Introduction to Sociological Methods. Prentice-Hall, 1988. 
5. Corbin, Juliet M. and Strauss, Anselm, Basics of Qualitative Research: Techniques and Procedures for Developing Grounded Theory, $2^{\text {nd }}$ ed., Thousand Oaks, CA: Sage Publications, 1998.

6. See http://www.zoomerang.com

\section{Appendix 1 - Semi-Structured Interview Categories and Supporting Fragments}

SFTP conferences are valuable because of:

- exposure to industry leaders

- exposure to government leaders

- predicting the future

- helping with careers

- explaining current state of industry

- efficient way to learn policy

- helps in thinking about telecom business planning

SFTP conferences are difficult because:

- lack of background or context makes it hard to understand speakers, boring; particularly issues with legal content

- speakers may speak over the head of audience

- moderator questions aren't clear

- context can be acquired over time or from course work

- lack of background is exacerbated for international students

- lack of international content

- some conferences may be redundant between conferences

- no relevance to technical interests; no linkages to technical courses

- understanding rapidly changing policy issues is particularly difficult without context

- topics are not compelling to technically oriented students

- attendance cheating

SFTP format:

- strong positions appreciated in debate oriented format

- panels can be somewhat redundant

- panelists can seem rushed

- following conversations (rather than presentations) is harder for non-native English speakers

- length is fine if content is compelling

- can go too late for social networking opportunities for some people

- later in the semester increases time conflicts with other coursework

- preview of content on SFTP site is helpful

- forcing students to ask questions is effective

- conferences earlier in the semester would be better

SFTP linkage to ITP curriculum:

- no preparation or review in seminar; this could help

- some explicit linkages to policy courses; implicit linkages high

- no linkages to technology courses 
Distance education issues:

- audience questions not clear

- no social networking with speakers

- not comfortable following up with speakers by email

- timeliness of posting ( $\sim 1$ week) is a problem when creates a pile up of assignments

- recordings can cut off beginning/introduction

- recordings are sometimes out of sequence

- panel shot makes it hard to tell who is speaking

Examples of key insights from SFTP conferences (fairly diverse)

- history of cable

- viability of third broadband pipe

- role of blogging in politics and media

- historical insights on cable industry

Social networking

- generally felt effective by on campus students

- can be clumping of industry folks that intimidates students

- also opportunity to meet ITP alumni

- $\quad$ several very positive experiences with in-conference and post-conference interaction

\section{Appendix 2 - Survey Instrument $(n=67)$ and Summarized Results}

1. How long ago did you attend or view your last Silicon Flatirons Telecommunications Program (SFTP) conference?

- Fall of 2005

- Spring of 2005

- Fall of 2004

- Earlier than Fall of 2004

- I haven't attended or viewed SFTP conferences.

2. About how many SFTP conferences have you attended or viewed?

- None

- One

- Two

- Three to Five

- Six to Ten

- More than Ten

3. Do you have an undergraduate degree in a technical field (science, technology, engineering, mathematics) or not?

- Yes I have an undergraduate degree in a technical field

- No, I have no undergraduate degrees in a technical field

- Don't have an undergraduate degree 
4. About how long ago did you earn your MS or ME in Telecommunications from the University of Colorado?

- I am studying for but have not completed a degree from CU ITP yet.

- I am not studying for a degree from CU ITP and do not have one.

- Within the last year.

- Within the last five years.

- More than five years ago.

5. How many years of professional work experience do you have?

- None

- One or part of a year.

- Two to Five years

- Five or more years

6. Are you an international student at CU?

- International student

- Not an international student

7. What do you or did you seek from your ITP education?

- Did not pursue an ITP education

- Primarily a technical education.

- Primarily a policy or business education

- A mixture of technology, policy, and business education.

8. On a seven point scale (where $1=$ Agree Strongly and $7=$ Disagree Strongly), please indicate the extent you agree with the following statements. (Weighted average of responses in parentheses.)

- SFTP helps explain current or predict the future state of the industry.

- There are too many conferences late in the semester.

- There is not sufficient preparation or review of SFTP conferences in TLEN 5600 Telecom Seminar.

- It is hard to follow conversations and debates.

- SFTP helps with career planning.

- SFTP is an efficient way to learn policy.

- The conferences end too late.

- The conference material is not relevant to the technical part of ITP

- It is much easier to understand SFTP conferences after a semester in ITP.

- Calling on students to ask questions at conferences is helpful.

- SFTP conferences are enjoyable.

- The moderated panel format is less effective than a presentation format.

- Useful topics for papers in other courses can be found in SFTP conferences.

- Learning policy through SFTP conferences is more efficient than from books or other types of courses.

- I lacked the context or background to understand SFTP conferences.

- The speakers spoke at too advanced a level. 
- The moderator didn't pose questions clearly.

- Previews of SFTP content on the SFTP site are useful

- Speakers were redundant within panels.

- Panels were redundant within a conference.

- Conferences were redundant.

- SFTP does not cover international topics enough.

- There was too little technical content.

- SFTP provides valuable exposure to Industry and Government leaders.

- Panelists were not given enough time to fully answer questions.

- The conferences are too long.

- The conference material is not relevant to the policy and business part of the ITP curriculum.

- SFTP panels are more effective when speakers take strong positions.

9. Do you have any other comments (positive or negative) on SFTP and recommendations for improvements?

10. On a seven point scale (where $1=$ Agree Strongly and $7=$ Disagree Strongly), if you watched any SFTP conferences as a distance education student (tape, CD, DVD, or streaming), please indicate how much you agree or disagree with the following. (Weighted average of responses in parentheses.)

- Questions from the audience were hard to understand.

- I was disappointed that I could not participate in social networking.

- I was not comfortable following up with speakers by email.....

- The recorded conferences were not made available on a timely basis

- The recordings were cut off or out of sequence.

- From the video, it is hard to tell who is speaking.

11. Do you have any other comments on the presentation of SFTP conferences through distance education?

12. On a seven point scale (where $1=$ Disagree Strongly and $7=$ Agree Strongly), if you could participate in the social networking opportunities during and after SFTP conferences, please indicate how much you agree or disagree with the following statements. (Weighted average of responses in parentheses.)

- I participated in social networking opportunities.

- I felt too intimidated to interact with speakers.

- I found it hard to interact with speakers and others in large groups.

- I tried to contact speakers by email or other means after the conferences.

- I found speakers accessible by email or other means after the conferences.

- Social networking with ITP alumni at conferences was valuable to me.

13. Do you have any other comments or suggestions on the social networking aspect of SFTP conferences? 
14. Do you have any other comments or suggestions about SFTP conferences in general?

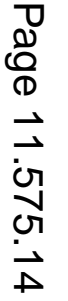

